\title{
Focusing Brick by Brick from Micro Level Material to Macro Level City Morphology: Green Healthy Brick Design
}

\author{
Shaikh Javaria Manzoor ${ }^{*}$, Park Jae Seung \\ Graduate School of Architecture Hanyang University, ERICA Ansan-si 426-791 Sa 3-dong, Korea \\ *Corresponding Author: javeria@hanyang.ac.kr
}

Copyright (c) 2013 Horizon Research Publishing All rights reserved.

\begin{abstract}
This paper intends to identify the chronology of compact city plan in Pakistan, where the grid is used to overlap the mixed used settlements. Theoretically there is little evidence that axial approaches are more accurate due to the module of the brick which is laid out in straight line for walls as hypothesized in the Harappa civilization, instead the square rectangular blocks appearing at Harappa. However, no study has combined the method accurately that the raw houses are constructed and streets are formulated at Harappa rectangular because they are based on the grid pattern due to its unit basic component brick proportion system. The grid iron is the negative space similar to mortar; the wall gives a grid pattern in elevation or $\mathrm{Y}$-axis, where as the grid iron is on $\mathrm{X}$-axis on the plan form.Concerning methodology the two pronged theory has been devised for this research. On the one hand the theoretical underpinning of the concept and realistic field survey was evolved whereas; on the other hand, analytical and evaluative steps were conducted to reach the realities of topology and typology. The tools and techniques used in documentation and analysis include map making using Depth map and Google Earth. For field photography, personal site visits were carried out with hired professional photographers. There were chronological sites that were visited, documented and traced for the evolution of Architectural Grid. These comprise: Indus Valley Civilisation Mohenjo Daro City, Harappa Punjab, Mehrgarh Civilization Balochistan, and Dwaraka Golf of Kamber Arabian Sea. Conclusively; this paper would prove that "the Nature 1" is the determinant of the precedents of grid pattern ay Harappa, which was otherwise perceived to be as a recent phenomenon of recorded history.
\end{abstract}

Keywords Ancient Cities, Indus Valley Civilization, Architectural grid, Urban Morphology, Space Syntax

\section{Introduction}

1 Nature here is defined as, natural straight movement of people, sun path, natural growth.
Martin Sauvage's book La brique et sa mise en oeuvre en Mésopotamie des origines à l'époque achéménide (1998) provided a comprehensive survey of brick in Ancient Mesopotamia. It measured the size of bricks and showed how they changed in format, looked at mortar types and bonding patterns at different sites and traced the use of fired bricks and sun-dried bricks. The Indus Civilisation flourished about the same time but no similar study has ever been carried out on its brickwork. This research aims to provide just such a study.

This research will follow a similar format to Sauvage's [1] study, tracing the brick's development from Indus Valley Civilisation, originally hand-moulded and sun-dried to moulded bricks and subsequently fired bricks. The research will start by mapping the sites and providing a detailed study of the archaeological reports for all the sites. Recording of bricks in archaeological reports tends to be mixed. The data from the reports will thus be supplemented by visiting each of the sites in turn and recording the sizes of bricks used, their manufacture and the way they are laid. By this method it will be possible to build up a very clear picture of the chronological development of the use of brick in the Ancient Indus Civilisation. This is important because the civilisation was one of the very earliest to use fired bricks and is thus believed to have had an influence on subsequent brickwork in other countries.

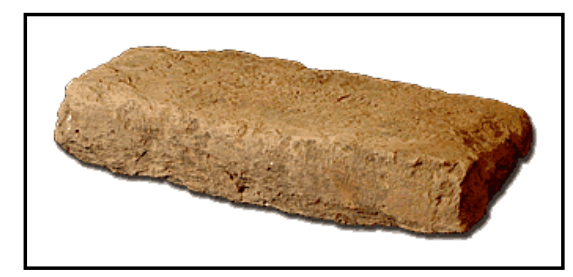

Figure 1. The brick as a unit for the grid pattern at Harappa

If brick modules differ significantly, then statistical analysis will be performed to identify the average or distribution within the wall (it may indicate different chronology). The focus of the survey will be on the key 
elevations that with more openings, changes in the brickwork type and degradations.

\subsection{Background}

These bricks were made in abundant number over a period of decades, moulded out of the mud-clay extracted from the banks of river Indus and Chanab, serving as a building component to sculpt twin cities of Harappa. These bricks, shaped in a perfect dimensional ratio of $4: 2: 1$, which till today is considered best for the laying and planning of the bond. This research mainly aims to compile, and formulate, a complete manual for these Indus Valley civilization brick, with accurate compositions, geometry, manufacture, and reuse, for the particularly designed modular brick and bonds, with unique and sustainable features. This brick was so perfect, that even centuries after its initial assembly, it was still an attractive building material for the construction contractors, few decades ago, and this is to note that today the railway linking Lahore to Multan in Pakistan is 4,600 years old.

Brick is referred to as one of the world's oldest professions; brick making is estimated to date back to early Indus Valley Civilization, possibly as far as 10,000 years ago. Clay from deposits around the Indus River was mixed with straw, shaped into brick units and sun dried. Through time, brick's popularity as a building material grew as it demonstrated the ability to withstand the harsh elements of nature and fire. As the use of brick flourished, the practice of sun drying was replaced with kiln drying and eventually kiln firing. From its humble beginnings, brick making has evolved into a thriving industry with state-of-the-art brick making equipment and kilning.

\subsection{Planning of the Cities}

Perhaps Indus Valley Civilisation, is constructed over three flanging brick platforms, these brick platforms are partially cantilevering (similar to a bridge) over the active river channels underneath. Therefore this city is also known as semi-amphibian due to its dual nature of functioning efficiently and surviving precisely in wet seasons of floods, this partially mobile platforms made the city earthquake resistant as well, due to its independent set of podiums, which hovers (floats independently) on the actual ground level.

Harappa historic mud bricks measure 10x20x40 cm and were mostly employed for the construction of massive platforms on which fired-brick dwellings were built, yet there is no study at present that explains how the Harappa manufactured mud bricks. The study of past craftsmanship involved in construction of the earthen platforms is of great importance for the structural stability of the fired-brick ruins but no archaeological investigation has been developed into this. While it can be assumed that mud bricks were manufactured with local soil there is no evidence on the use of additives or straw.
Brick as the mode of construction varying from sun-dried brick to fired brick depending on the desired strength requirements and location. For example, the streets where wear and tear was obvious, fired bricks were used, similarly, for the sewerage water drainage purpose, water prove, fired bricks were use, for the well and baths as well. Whereas for the granary platforms, house construction sun dried bricks were used. The floors in most of the rooms were made of beaten earth. Moreover some rooms were paved with baked bricks. These rooms usually had drains in the floor. Archaeologists believe that these were probably bathrooms or rooms used for bathing. The waste water was carried out of the building through pipes which emptied into a long drain. The drains ran down the streets and out of town.

The manufacturing of mud-bricks followed a seasonal pattern with May-June being the time for packing and molding the bricks. This was the period after the spring rainy season, so water would have been plentiful. The drying period began immediately after, taking advantage of the dry summer months. Building started in late July or August when the ground had dried enough to begin laying foundations.

Finally, I would like to point to the evolution of building practices as evidence of complexity. In earlier periods of Indus Valley Civilization history, construction materials, such as packed clay, were not used effectively and could not support a growing urban metropolis. As dried mud-brick and then fired mud-brick appeared, structures such as baths, granaries, and multiple storied houses were now possible to construct. Complex societies cannot exist without the materials needed to support city-building.

One of the hypothesis presented as a possible reason for the decline can also be reciprocated the brick manufacturing, that is soil erosion due to very large scale brick-manufacture, this leads to floods, earthquake and increase in population \& livestock - exhausted the natural resources. There is also plenty of trace of hydrogen on the bricks as well, which also leads to another hypothesis of employment of a man made planned mass destruction, since this nation was advocating true democracy (a modern ideology: and were aware of their civil rights) at a primitive era, where other simultaneously existing nations were ruling and surviving on the prejudiced doctrine of sheer slavery. And such a self-governing idea (Indus Valley civilisation) will generate rebellions and ultimately could have destroyed their discriminatory government (e.g. Egypt and Mesopotamia).

The urban grid is a very dominant type of street network in modern cities. It provides an efficient mobility for humans as well as various transportation modes. The urban grid system has a long history of ubiquitous influence. Miletus, a colonial Greek city, was rebuilt on a grid system around BC 479 by the first recorded town planner Hippodamus [7]. Infect, the Greek orthogonal planning tradition was influenced by ancient civilizations such as Egypt and Mesopotamia. Despite the dominant use of grid system in the ancient cities as well as modern cities, urban scholars have not rigorously explored the prototypical origin of urban grid system in the history of urban morphology. 
To justify that the grid plan is the most modern as well as the most primitive type of approach towards urban morphology, this study focuses on Harappa (BC 3000) and Dawarka which is inferred here as today's Manhattan based on the urban morphological standards of orthogonal grid. Second, the ancient city of Mehargarh (BC 7000) located at the eastern Baluchistan area, which is contemporary to the Neolithic site of Çatalhöyük (BC 7500), Turkey.

\section{Materials and Methods}

In continuation with the efforts of [12] re-excavation of the origin of urbanism and similar to [9] new approach to ancient urban planning; this paper draws the motivation behind the grid plan. Grid favors the constructive performance that could be successfully hosted upon the eternally valid podium which a grid permits for a city. Consequently, much earlier prototype of grid system has been found in ancient cities such as Harappa in the Indus Valley civilization.. Study of the consecutive grid plan of a town and other pertinent chronological and morphological suggestion from the original possible date on will reveal the expansion of the grid town plan in terms of apparent external growth and internal change over generation, provided and insofar as the plans present adequately the three element compounds of street arrangement, plot configuration, and building coverage. [2]

\subsection{Literature Review}

The literature review defines orthogonal grid, by synthesis of four different determinants of urban grid system. Firstly alignment and distribution of spaces on basis of public and private activities, mixed used density, and overlap in form of semi lattice (jointed) rather than a tree diagram (disjointed) $\mathrm{C}$. Alexander [15]. Secondly circulation of people, i.e. how grid can facilitate, people to reach from one point of city to the other, and this also includes how people visually connect. Third determinant is the geometry and the geometrical components which make the grid, which include right angles and straight lines which supports growth, change and efficient security through eyes on the streets [6]. Finally density this incorporates both the fringe belt as well as the burgage cycle process of Cozenian theory [1] of expansion of urban morphology Lang [8]. The Homo is an imaginative character representing human inhabitants in all the urban form discussed here, furthermore Homo represents evolution to maintain a homogeneous approach towards argument building flow in the spatial-temporal longitudinal approach, and he adds slight drama and maintains interest throughout the study.

This study conducted a comprehensive literature review to examine the theoretical backgrounds for grid which provides space organization and content management and it facilitated time and cost management along with the efficient function of the grid. Syntactically it provides positional, proportional, divisional, and sequential morphology. Hillier, [5] interprets the urban grid as the most powerful theorem and practice of urban spatial engineering in urban planning history. Although the most important characteristic of the urban grid is that it creates a foundation amenable to producing efficient land uses. Theoretically the grid is the means by which a town becomes a "mechanism for generation contact" and it does this by ensuring that a typical origin-destination trip will take a pedestrian past several outward-facing buildings (Hillier, 1999).'.

\subsection{Limitation of Previous Literature}

The soft gird can accommodate density as it is the primary characteristics; the soft-grid is becoming as finite and definitive as a grid operates. Its interface and interaction and user experience does not look like a grid. The grid is softening the ancient linear movement of measurement, definition and adjustments. The second step is to define the peripherals for the fundamental connections. This first line is defined as a quasi- perpendicular intersection link and is the spine for the margin of the site.

This center less system is open to grow with the quasiparallel lines along the intersectional straight lines. The soft grid interfaces the interference, to east-west, deviating from the rectilinear orthogonal lines and does not have to follow the given pre configured forms. But soft grid could adapt, bent, curve and interwove the lines. Thus could occasional be irregular crossing the dimensional configuration.

The third step is to adopt the grid according to the topography of the site, the soft- grid is not soft due to the curvature but it is soft because of the form generative approach of merging continuity and accessibility. The fourth step is the construction of the field containing voids, hence the grid could become a form itself, the grid could fade away, and the end result if not a formal conventional grid appear, but functionally it is operating like a grid.

Secondly if the grid still remains a grid if, the formal final envelop is not restricted, and if the outer boundaries are not defined. She emphasized on the operational progress of the grid, hence grid is not a form but an effect 'grid effect'. The operational grid set free the formal grid i.e. the performance of the grid is exposed beyond the appearance of the grid. The gridiron formal resolution is dissociate from grid can be the grid effect. It's not necessary for the grid effect to produce simply grids.

\section{Case Study Harappa}

Ancient cities were planned on the basis of urban morphology and they followed common sense notions for urban girds, Michael Smith [9]. As Spiro Kostof [7] is one of the few scholars to use the term grid lay out, which referred to orthogonal planning, that the earliest city in the Middle East Jericho (8000-6000 B.C). Later, on the other advanced 
civilisation arose along the Nile in Egypt and in Mesopotamia along the Tigris and the Euphrates; these towns were also planned on doctrinaire orthogonal grid systems.

Source: Harappa Section across the western defenses oh the citadel ("Mound AB") at HPXXX (Sir Mortimer Wheeler, The Indus Civilization page 19) M. Wheeler (1953)

Harappa was perfectly patterned gridiron, as precise as modern New York City, serving 35,000 inhabitants; this gridiron contained the covered ducks to refrigerate the grains. A plumbing substructure which achieved premium of hygiene with parallel underground sewage system moving towards Indus River independent of the city's drinking water supply Higgins [3]. Urban Process in the Indus Tradition: A Preliminary Model from Harappa, Jonathan Mark Kenoyer, Excavations on two of the major mounds at Harappa have revealed traces of an early settlement, a transitional phase of development, and several phases of full urban and post-urban occupation. A preliminary model is presented for the development of Harappa as a city in the wider context of the Indus Tradition, 2000-2001http://harappa.drupalgardens . com/category/articles/pdf?page $=1$

Over time, Homo showed major progress, he was evolving and becoming more humane, he was discovering more material and career and more formalizing planning techniques, Snooks [11] figure two represents all the determinants of the grid. Furthermore as Rousseau [14] refers that human learn from each other and there is a need to have more vicinity and closeness amongst human, this was valid from pre-historic time (Figure. 2).

The urban morphology for Homo depended upon his way of vocation earlier then agriculture $(8000 \mathrm{BC})$ native were making tools to sells, this is the pivotal point in history where he has tool to construct therefore he planned dwelling towns [13].

Note: (Indus civilisation contemporaneously arisen which lies in the deeper layers of Harappa and other sites, which cannot be explored due to water-logging).

These towns were based on well calculated sun orientation and the understanding of Homo for geometrical and ergonomically proportional features represents the intellect and precision of urban morphological decision. Moreover the 1:2 rectangular proportions for the room and the 45 degree angle overlapped shift which is parallel to north qualifies Homo as an urban designer for this earliest cities.

The larger site have satellite towns as an urbanism pattern, the temporal model traced back the history of urbanism to Mehargarh, Baluchistan.

Mehargarh Kachi had a deep long history of urbanization in $7^{\text {th }}$ millennium BC, before Mehargarh Architecture and Burials at Balouchistan. The figure two above shows that there are simple multi rooms buildings, the spaces between the rooms provide space to burial and for domestication for food-production economy. The village farming community was founded and the start of Harappa Civilization started.

The Figure 3 represents how grid is an axial spine for functioning society. Grid provides physical mechanism within urban space to respond the varied requirement of that society and its individuals, shelter, rearing children, working transportation, education, the supply of goods, other social and cultural services and recreation. As these essential needs changes over time, so does the character of the grid for the townscape. Hence Grid is subject to historical development. Cozen(2004)

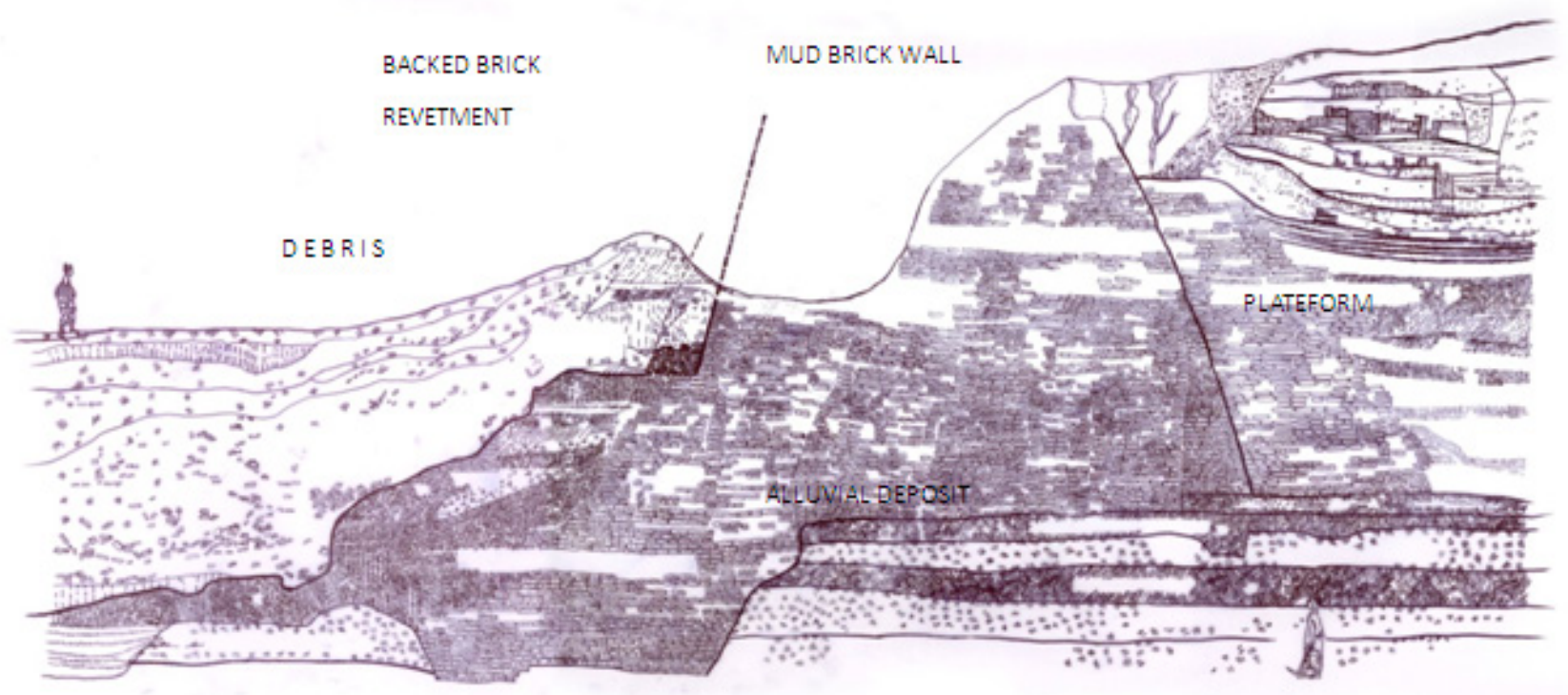

Figure 2. Representation of the excavation systems at Indus Valley Civilization 


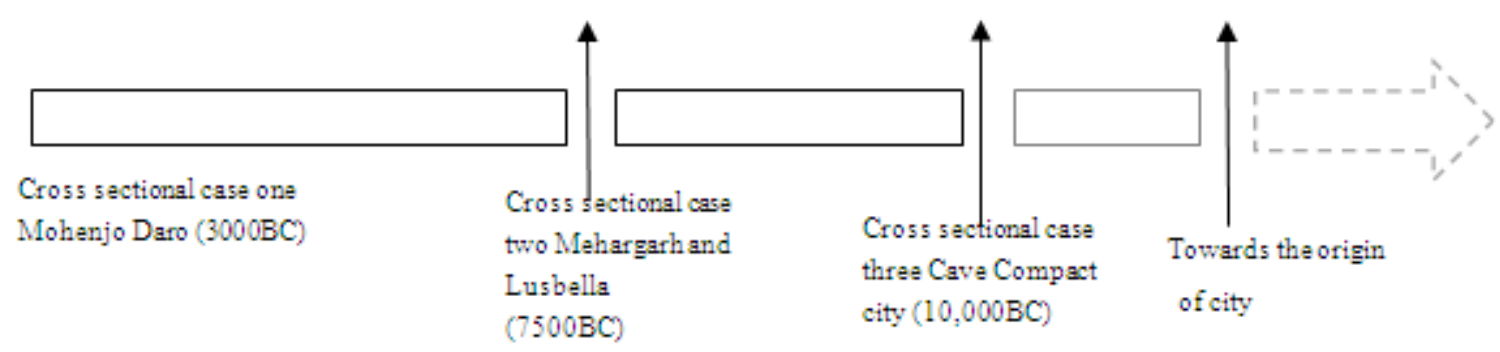

Figure 3. Research Model, A sectional temporal research method model applied at a local scale (micro level grid origin)

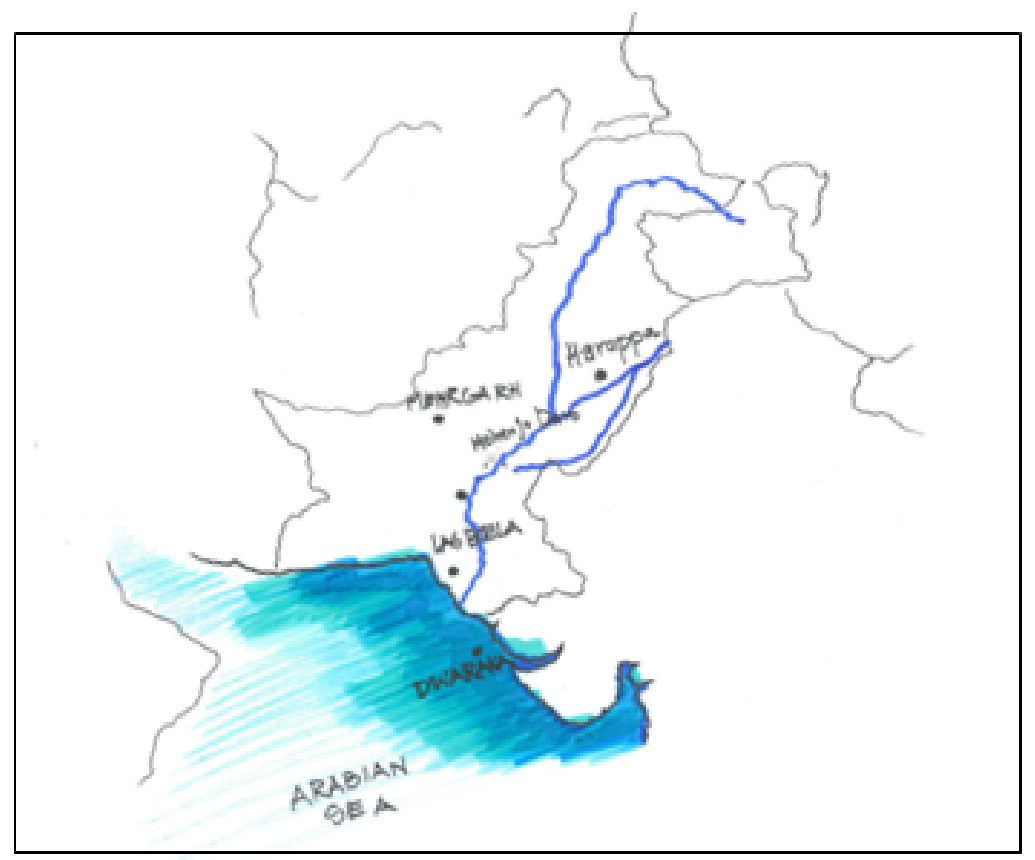

Figure 4. Locations of Case Study Areas 

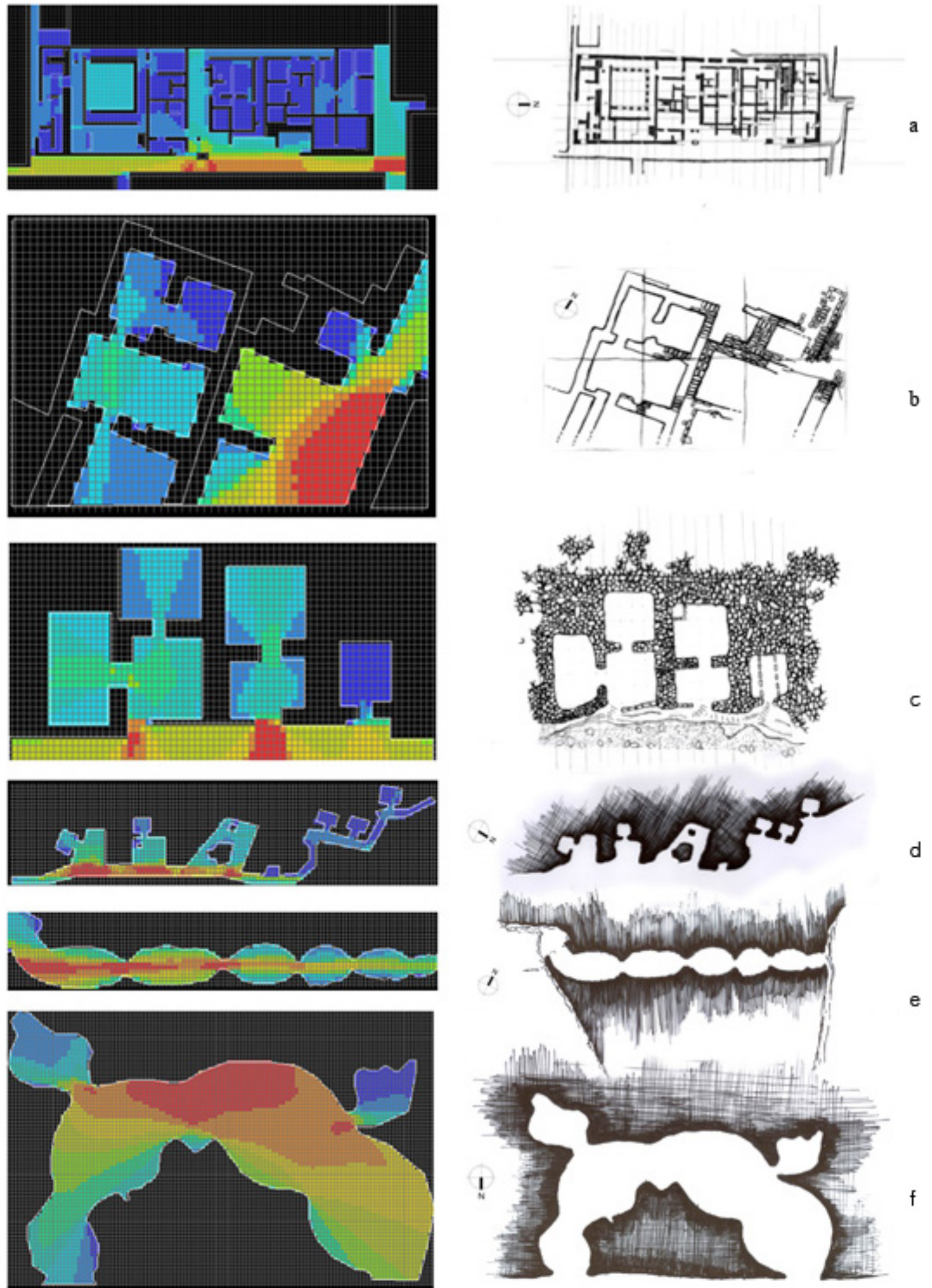

Figure 5. Depth map representation the movement and arrangement of alignments, and the urban grid, supplementing the distribution of built form densities in the historically evolving city. 
Mohenjo Daro(2500 BC), b. Mehrgarh (6500BC) c. Gundrani Cave City (7000BC) Balouchistan, d. Seven cave at Sehwan (10,000BC), e. Devil Mouth first, at Shahdee Shaheed, f. Devils mouth second Rakas jo Rohro, Rohri Hills Sindh.

For this research a similar model of analysis is derived as an archeologist finds the different grades of layers, while excavation, the newest layer is the one which is the top most layers, and as he excavates further the origin is found at latter stages or layers. Hence the conceptual framework used here for the analyses of individual cases is to determine the variables of grid system used at different stages. This is done by analyzing the newest civilization and then retrogressively pushing back the history of grid.

\begin{tabular}{l}
\hline Ground level \\
\hline Layer one: Manhattan (2013) \\
\hline Layer two: Mohenjo daro and Dwaraka (2500BC) \\
\hline Layer three: Mehargarh and Çatalhöyük (7500BC) \\
\hline Layer four: cave orthogonal urban morphology $(10,000 \mathrm{BC})$
\end{tabular}

Figure 6. A retrogressive longitudinal research method model applied at a global scale (macro level grid evolution)

"Since space syntax is a way of researching cities to understand how social and economic processes shape over time. The finest aspect of space syntax is its sets of methods for analyzing patterns of space- or spatial configuration- in the built environment. These methods both uncover spatial structures in cities and relate them to the way people move, stop, and interact. The figures represent the axial analysis (for analysis of the network of street and walkways cities) and "visibility graph analysis" or VGA (for analysing patterns of visual fields in Public space).

\subsection{Determinant one: Comparative Analysis of Mixed Use, Public Private Activities over Lap Study from Hard Grid to Soft Grid}

A grid for a city defines special and functional nature as a whole, without the grid, city would eliminate all the properties of density, good spatial scale, controlled juxtaposition of uses, continuity, and integration of well-ordering for the city depends on the grid [5].

This characteristic was fulfilled by Homo's well designed compact cities at different times the figure. 1 and table 1, synthesis the aspects he was aiming to achieve.

The transformation of the burgage pattern is effected by regular building repletion of individual burgage and by a metamorphosis of the plot boundary pattern. Building repletion is a cycle process (the burgage cycle). Plot metamorphosis is the process whereby the plot pattern is an original burgage series is altered in various ways, especially notable being the amalgamation of neighbouring burgages to provide site for more commodious houses. [2]

Hierarchical nesting of morphogenetic region (principal of): morphogenetic regions form a nesting hierarchy within the townscape in which small- scale townscape units 'nest' within larger ones, which themselves 'nest' within yet larger units. For example, morphotopes, the smallest building groups of distinctive period mixture or period dominance, contribute collectively to the delineation of neighbourhood units, composed of either street units or precinctual units, which then aggregated to town quarters, representing traditional genetic plan units, which in turn comprise a major region, such as the traditional core or Old Town.

Table 1. Evaluation of the individual case studies and analysis

\begin{tabular}{|c|c|c|c|}
\hline $\begin{array}{l}\text { Nature as Determinants } \\
\text { Of grids }\end{array}$ & $\begin{array}{c}\text { Case one } \\
\text { Manhattan }\end{array}$ & $\begin{array}{l}\text { Case two: } \\
\text { Harappa }\end{array}$ & $\begin{array}{l}\text { Case three: } \\
\text { Dwaraka }\end{array}$ \\
\hline Movement of people & $\begin{array}{l}\text { Main street grid internal } \\
\text { linear circulation Avenues }\end{array}$ & $\begin{array}{c}\text { Movement of people in Primary } \\
\text { streets secondary street and } \\
\text { tertiary street }\end{array}$ & Accessible street lay out \\
\hline Movement of sun & Grid parallel to North side & $\begin{array}{l}\text {-East west streets for the sun light } \\
\text { after mid day }\end{array}$ & Parallel to North Side \\
\hline Geometry & $\begin{array}{l}\text {-Right angle grid } \\
\text {-diagonal overlap }\end{array}$ & $\begin{array}{l}\text {-Right angle } \\
\text { - Lines } \\
\text {-Orthogonal } \\
\end{array}$ & Orthogonal axis lines \\
\hline $\begin{array}{c}\text { Growth } \\
\text { Change } \\
\text { Expandability }\end{array}$ & $\begin{array}{l}\text { Vertical } \\
\text { High rise }\end{array}$ & $\begin{array}{l}\text { according to a vertical grid the } \\
\text { new structures could be added }\end{array}$ & surrounding space for expansion \\
\hline $\begin{array}{l}\text { Security safety and } \\
\text { movement of the eyes for } \\
\text { guard and learning }\end{array}$ & $\begin{array}{l}\text { Limited movement of eyes } \\
\text { due to high buildings }\end{array}$ & Grid supports Interaction & Guarding the storage area \\
\hline
\end{tabular}



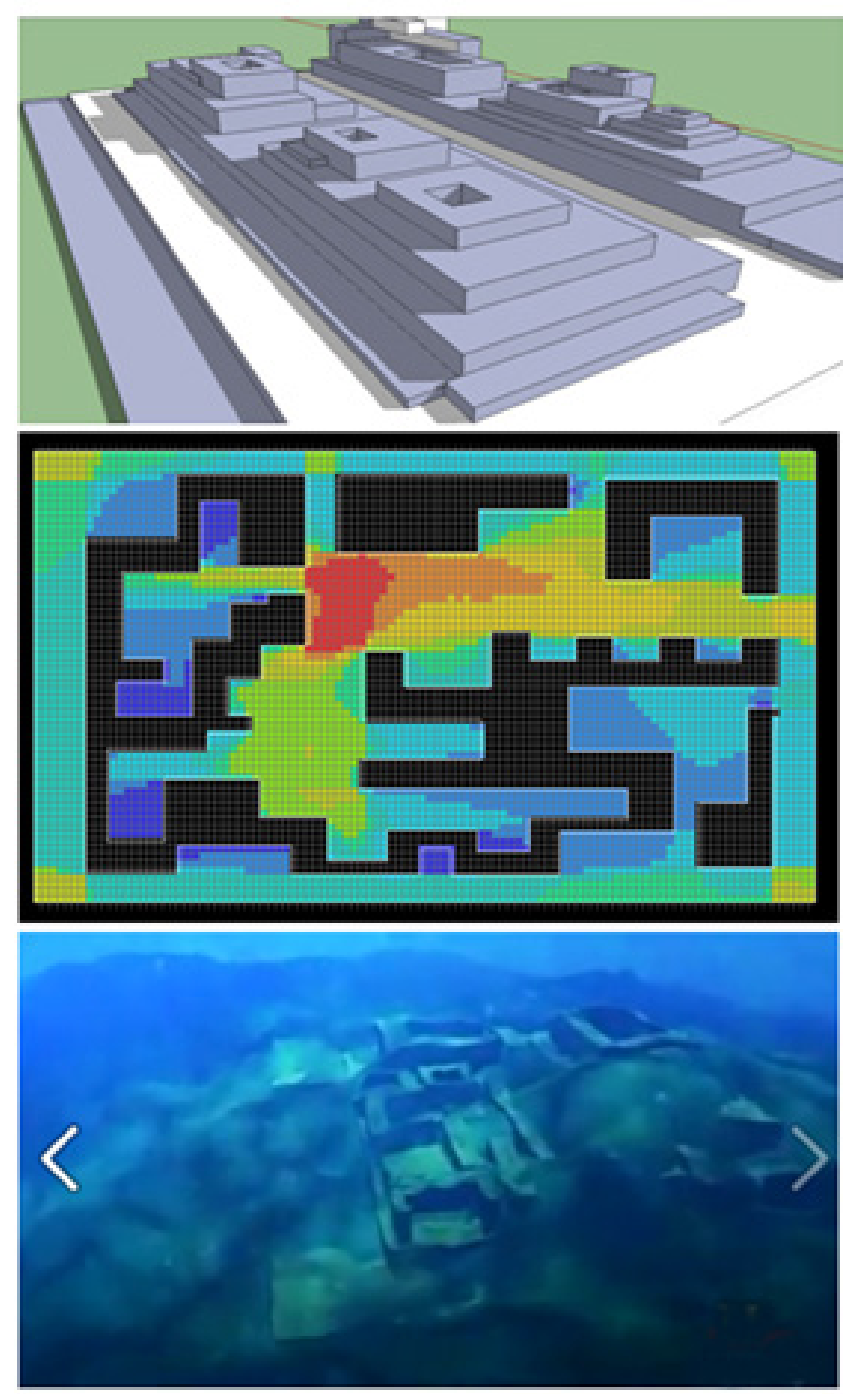

Figure 7. The figure represents the author's quasi-study for the geometrical city plan of the Ancient city of Dwarka (currently submerged in Arabian Sea underwater archeology) contemporary to Harappa.

Source: Graham Hancock documentaries Underworld: Flooded Kingdoms of the Ice Age (2002) accessed on 15 May, 2013

http://www.youtube.com/watch?v=GQuMGjXfF7Y

And The history Channel broadcasted on May 1, 2012, The ancient city of Dwarka.

http://www.youtube.com/watch?v=3tq71v9rbcY

In Figure 7 the space syntax idea is applied on a primitive city, spatial patterns of Modern cities, [2] to understand the grid pattern, here the connectivity of a line is the number of lines that are directly connected to formulate the entire morphology. The Urban development was not discontinuous, with the mature Harappan civilization, continuity is understood and weighted with Pre- Amri site where isolated domestic quarters, in form of workshops.

Fringe-belt development: the formation or intensification of a fringe belt of mixed and generally space- consuming land uses on the urban fringe during periods of reduced outward residential growth. The process passes through the fixation phase, the expansion phase, and the consolidation phase.

This brings us finally to the necessity of research in historical geography within urban studies, a meeting-ground of geographers and historians. Here, continental work seems more advanced, partly because of the traditional greater interest of urban historian in using topographical evidence in existing town plan for their own purpose, thus facilitating the collaboration of geography and historians. In philosophical terms such a complex combines the three realms of existence in geographical space, namely, inorganic or physical nature, organic or biological nature, and human society, in one integrated system of interaction forces.

Geospheric diversification

Zonal diversification:

A zonal diversification

The natural region: it is the relief units resulting from this development- Mountain and valley, hills, plateaus, basins, and plains of different types- that have separated or in combination generated dynamic subsystems, each with its individual traits in terms of geographical position, extent, material components, interacting forces, and their particular combination. Caniggia's theory: human history is the same as natural history each involved the processes of birth, growth, prime of life and death. And there was a clear implication of the products of human accomplishments.

\subsection{Case Study Analysis}

The case studies section of this paper defines how the town planners of Harappa prior experience of grid planning from the Mehargarh grid planning, though the hilly typology and topography was different yet the grid morphology was same. The origin of the grid for Egypt and Mesopotamia could follow religious orientation, which is not true for Harappa, where religious significance as basis of grid is not applicable. According to the proponent for grid plan it is legible, accessible, and efficient, the system of order which controls the landscape as well as symbolize ordered system for over inhabitants. The paper recognizes the change in pattern according the usage for the site.

\section{Evaluation and Synthesis of the Individual Case Studies and Analysis}

The scale of determinants for the varying grid sophistication levels from case five to case one, in a retrogressive manner is suggested in this table. The primary reason for the origin of the grid is accessibility of linear route case five. Further evolvements to the intricate systems were added over time as Lusbella caters for proportions of density. Continuity and the spatial scale resulted the grid geometry to grow complex by overlapping with primary secondary and tertiary street networks, which is valid for case two Mohenjo 
Daro plan where space use is more controlled, and order is further integrated.

Conclusively, this paper proves that nature; the direction of sun and air circulation, movement patterns of people, public and private segregations planned over the grids. Moreover sanitation needs, resulted in the geometrical patterns for urban morphology and finally the most natural inherit need which is security, are determinant and precedents of grid pattern since late Stone Age which is otherwise credited to modern philosophy.

\section{Conclusion}

Over time our common global ancestor Homo was evolving and becoming more humane, by technology advancement as referred by Snooks [11], he was discovering more material, more career and more planning techniques hence grid plan was also adapted as the most initial effort towards formal civilization, he showed major progress, over time. Hence as Jean-Jacques Rousseau refers that human learn from each other and there is a need to have more vicinity and closeness amount human, this was valid all the way since pre- historic time. Moreover the phenomena mentioned by Rousseau (1962) famous wrote, could be the main reason for the advent of urban morphology, and orthogonally planned grid patterns for the city to inhabit maximum occupants in the most compact form.

The globally valid grid phenomenon has been with man since long and is expected to stay in the vocabulary of urban morphology further longer. Given that the grid modeling of space will continue to exist the development of further understand is critical. Here the determinant of grids can be simplified as below:

First determinant is concept of rational alignment of living spaces to smooth the progress of the movement of people and assist their approach.

To have a sense of community by connectivity of lines of sight and facilitate cone of vision.

Second determinant of grid is alignment with sun path and bringing in calculated sun light.

The linkages and alignment of connectivity of public and private places on the grid infrastructure protects security and prevents crime, due to visual harmony

The grid facilitated expansion and amendments for the city which grow over time according to economic, social, cultural and environmental prerequisite

This paper is a continuation with the efforts of Cozen theory (1932-1998) that emphasised on the intensive documentation of the field survey to develop concepts subsequent to the observable phenomena and so fabricate a morphological theory of the townscape.

The grid is an orthogonal layout which is an innovative system in the history of urban morphology. However, not much research was done about the primary origin of the urban grid system. This study illustrated that the origin of urban at the Indus Valley Civilization is related with the prototype of brick form. At macro level the city had same morphology as at micro level.

\section{REFERENCES}

[1] Martin Sauvage. (1998) La Brique et sa mise en oeuvre en Mesopotamie: Des origines a l'epoque achemenide. Paris: EDITIONS RECHERCHE SUR LES CIVILISATIONS,

[2] Michael P. Conzen, M. R. G. Conzen (2004), Thinking about Urban Form : Papers on Urban Morphology, 1932-1998 ISBN-10: $0820472034 \quad$ ISBN-13: 9780820472034

[3] Higgins, H. (2009) The Grid Book (MIT Press, Illinois).

[4] Hillier, B. (2012) Space is a Machine (Cambridge University Press, Cambridge).

[5] Hillier, B (2007) Space is the machine: a configurational theory of architecture. Space Syntax: London, UK.

[6] Jacobs, J. (1961). The Death and Life of Great American Cities (Random House, New York).

[7] Kostof, K. S. (2009) The city shaped: urban patterns and meanings through history (Bulfinch Press, Boston). New York.

[8] Long, Y., Baran, P. and Moore, R. (2007). The Role of Space Syntax in Spatial Cognition: Evidence from Urban China. The 6th International Space Syntax Symposium Proceedings, Istanbul.

[9] Smith, M. (2009). 'V. Gordon Childe and the urban revolution: A historical perspective on a revolution in urban studies' Town Planning Review 80(1), 3-29.

[10] Smith, M. (2007) 'Form and meaning in the earliest cities: A new approach to ancient urban planning'. Journal of Planning History vol 6, no.1:3-47.

[11] Snooks, G. D(2002). 'Uncovering the Laws of Global History'. Social Evolution \& History vol. 1 no. 1, 25-53.

[12] Soja, E. W. (2000) Postmetropolis: Critical Studies of Cities and Regions (Blackwell Publishers, Malden, MA)

[13] Possehl, G. (2003) The Indus Civilization: An introduction to environment, subsistence, and cultural history.

[14] Rousseau, J. (1762) Émile, Cities are the abyss of the human species. (Les villes sont le gouffre de l'espèce humaine.)The word gouffre is sometimes translated as sink instead of abyss.

[15] Alexander, C.A City is Not a Tree, Architectural Forum, (April 1965). 58 62, and (May 1965), 